\title{
Sustentabilidade Ambiental: Estudo em uma Instituição de Ensino Catarinense
}

\section{Environmental Sustainability: Study in an Institution of Learning Catarinense}

\author{
Silvana Dalmutt Kruger \\ Mestranda em Ciências Contábeis - UFSC \\ Discente do Programa de Pós-Graduação em Ciências Contábeis da UFSC \\ Programa de Pós-Graduação em Contabilidade - Centro Sócio Econômico da UFSC - \\ Trindade - Florianópolis - SC - 88040-900 \\ silvanak@unochapeco.edu.br \\ Elisete Dahmer Pfitscher \\ Doutora em Engenharia de Produção - UFSC \\ Professora do Programa de Pós-Graduação em Ciências Contábeis da UFSC \\ Programa de Pós-Graduação em Contabilidade - Centro Sócio Econômico da UFSC - \\ Trindade - Florianópolis - SC - 88040-900 \\ elisete@cse.ufsc.br \\ Vivian Osmari Uhlmann \\ Mestre em Ciências Contábeis - UFSC \\ Professora do Departamento de Ciências Contábeis da UFSC \\ Programa de Pós-Graduação em Contabilidade - Centro Sócio Econômico da UFSC - \\ Trindade - Florianópolis - SC - 88040-900 \\ vouhlmann@gmail.com \\ Sergio Murilo Petri \\ Doutor em Engenharia de Produção - UFSC \\ Professor do Programa de Pós-Graduação em Ciências Contábeis da UFSC \\ Programa de Pós-Graduação em Contabilidade - Centro Sócio Econômico da UFSC - \\ Trindade - Florianópolis - SC - 88040-900 \\ smpetri@gmail.com
}

\section{Resumo}

Este artigo tem como objetivo geral analisar a sustentabilidade ambiental de uma instituição de ensino superior catarinense, com base no Sistema Contábil Gerencial Ambiental SICOGEA - Geração 3. O estudo foi desenvolvido mediante a realização de entrevistas junto aos responsáveis por diversos setores da instituição de ensino, com o propósito de responder a uma lista de verificação com 154 questões, que possibilitou estudar os aspectos e impactos ambientais, bem como o índice de sustentabilidade ambiental da instituição. Os resultados obtidos sugerem que a instituição de ensino superior apresenta um bom nível de responsabilidade ambiental, com índice de 70,60\%. Ressalta-se que não se identificaram critérios deficitários dentre os 9 critérios analisados. Os critérios de prestação de serviços e atendimento acadêmico atingiram o índice de $89,2 \%$ e a responsabilidade social na instituição obteve índice de $82,2 \%$, considerados índices adequados de sustentabilidade pelo método adotado na pesquisa. Os demais 5 critérios analisados são considerados bons, ou seja, existem ações praticadas na instituição para além da legislação e projetos que buscam valorizar o meio 
ambiente. O estudo propõe um plano resumido de gestão ambiental, visando contribuir no desenvolvimento de ações de conscientização e redução dos processos causadores de impacto ambiental da instituição de ensino superior.

Palavras-chave: Sustentabilidade ambiental. Contabilidade ambiental. Instituição de ensino.

\begin{abstract}
This article aims at analyzing the environmental sustainability of a higher education institution in Santa Catarina, based on Environmental Management Accounting System SICOGEA - Generation 3. The study was developed by conducting interviews with those responsible for various sectors of the educational institution for the purpose of responding to a checklist of 154 questions, which allowed the study of the environmental aspects and impacts, as well as the environmental sustainability index the institution. The results suggest that the higher education institution has a good level of environmental responsibility, with a rate of $70.60 \%$. We emphasize that no statistical deficit criteria of the 9 criteria analyzed. The criteria for the provision of academic services and service index reached $89.2 \%$ and social responsibility in the institution index gained $82.2 \%$, levels considered adequate by the method adopted for sustainability research. The other five criteria examined are considered good, ie, there are actions taken at the institution in addition to legislation and projects to enhance the environment. The study proposes an environmental management plan summary, in order to contribute to the development of awareness-raising processes and reduction of environmental impact to the institution of higher education.
\end{abstract}

Keywords: Environmental Sustainability. Environmental management. Educational Institution.

\title{
1 Introdução
}

O cenário mercadológico onde as entidades estão inseridas passou a ser observado pelos stakeholders com elementos de responsabilidade social e ambiental. Neste contexto, as entidades precisam atender além dos compromissos econômicos, àqueles voltados ao desempenho social e ambiental.

De acordo com Trevisan et al. (2008, p. 01), o final do século XX é marcado por dois grandes temas: "a globalização dos mercados, que levou a concorrência organizacional a uma dimensão mundial, e o aumento da preocupação ambiental, traduzida pelo desejo de harmonizar a aparente contradição entre o desenvolvimento e a preservação do meio ambiente". Neste sentido, Campos, Estivalete e Machado (2008) enfatizam que as entidades passaram a conviver com uma série de desafios, incluindo as preocupações para com o meio ambiente e as inquietações com as questões sociais visando encontrar alternativas sustentáveis para o desenvolvimento local e regional.

Ferreira, Cunha e Rosseto (2008) evidenciam que se torna pertinente analisar as mudanças ocorridas nas organizações visando uma gestão ambiental responsável, tendo em vista que cada vez mais estão sujeitas às exigências de mercado, a legislação, e ao olhar da própria comunidade que passou a observar as ações e práticas ambientais.

A contabilidade cumpre seu papel de controle e planejamento, atendendo as necessidades dos gestores inclusive para com tais demandas de responsabilidade social e ambiental, a partir de modelos e propostas voltados a auxiliar no gerenciamento dessas práticas, os Sistemas de Gestão Ambiental (SGA).

O estudo de Pfitscher (2004) apresenta um modelo de SGA, o Sistema Contábil Gerencial Ambiental - SICOGEA, o qual visa oferecer informações sobre a sustentabilidade 
ambiental, auxiliando os gestores na análise das ações empresariais sobre o meio ambiente. O SICOGEA recebeu novo aporte proposto por Nunes (2010); o SICOGEA - Geração II onde a proposta alterou a estrutura do método, com novos indicadores, nova estrutura da lista de verificação e novo formato para as respostas (peso de zero a 5 cinco) com atribuição de pontos diferentes a critério do analista.

Uhlmann (2011) apresenta novos ajustes e melhorias ao SGA, salienta a importância da metodologia proposta pelo SICOGEA - Geração 3, que consiste em um modelo de gestão aliado à Contabilidade e à Controladoria Ambiental, o qual possibilita diagnosticar e gerenciar os aspectos e impactos ambientais das entidades.

O estudo de Pieri (2010) aplicou o método SICOGEA - Geração 3 numa instituição de ensino comunitária da região sul do Estado de Santa Catarina, a UNESC, analisando a sustentabilidade da entidade a partir de uma lista de verificação e da mensuração dos critérios do método. Neste sentido, o estudo buscou investigar por meio da lista de verificação do SICOGEA - Geração 3, utilizou-se os mesmos critérios do estudo de Pieri (2010) a fim de realizar um estudo comparativo com outra instituição de ensino da região oeste do Estado de Santa Catarina, a Unochapecó, a fim de estabelecer um benchmarking entre as instituições comunitárias de ensino superior.

Neste sentido, e diante da importância desta temática, o presente estudo tem por objetivo analisar a sustentabilidade ambiental de uma instituição de ensino superior catarinense. A partir do índice de sustentabilidade ambiental obtido por meio da aplicação do SICOGEA - Geração 3, identificam-se os principais processos causadores de impactos ambientais e propõem-se um plano resumido de gestão ambiental para a instituição visando contribuir com a implementação de melhores práticas ambientais.

O estudo evidencia a contribuição do SICOGEA - Geração 3 como sistema de apoio ao gerenciamento das ações e práticas ambientais para as entidades, bem como na identificação de alternativas para a redução dos impactos ambientais resultantes das atividades desenvolvidas, inclusive para as instituições de ensino.

\section{Fundamentação Teórica}

Este tópico aborda as temáticas relacionadas ao estudo, contemplando a responsabilidade social e ambiental, gestão social e ambiental e as instituições de ensino, bem como, contempla estudos anteriores realizados sobre o tema.

\subsection{Responsabilidade Social e Ambiental}

No atual cenário mercadológico o contexto social e ambiental passou a ser observado pelos stakeholders, bem como, o planejamento empresarial não pode mais ignorar o meio onde se insere, de modo a evidenciar suas ações ou práticas voltadas a responsabilidade social e ambiental.

Segundo Leonardo (2006) as questões voltadas ao meio ambiente e a preocupação com o ecossistema são o primeiro passo em direção à responsabilidade social e ambiental, tendo em vista que uma decisão equivocada em relação ao meio ambiente, pode causar efeitos para além do contexto da própria empresa e comprometer o futuro de muitas gerações.

Para Mazzioni, Tinoco e Oliveira (2007) as empresas preocupadas com sua responsabilidade social devem assumir uma postura proativa nas soluções dos problemas sociais, cultivando e praticando em suas operações um conjunto de valores éticos como referência.

A responsabilidade social e ambiental deve ser entendida como um princípio de conduta para as práticas empresariais, ou seja, nos processos que envolvem as atividades das 
entidades, devem ser analisadas e questionadas quanto a possíveis melhorias de eficiência, de desempenho, mas também para que tais processos sejam socialmente responsáveis.

Segundo Ferreira (2003, p.33):

[...] os executivos das empresas dificilmente escolhem a alternativa que menos danifique o meio ambiente. Embora esse seja o objetivo a ser alcançado, num mundo que se depara com questões tão primordiais como a fome, a educação, a saúde, enfim, condições de sobrevivência do homem que a humanidade ainda não conseguiu resolver, decidir em favor de ações que preservem o meio ambiente tornase mais difícil.

Neste contexto Ferreira (2003) ainda enfatiza que a sobrevivência do negócio do ponto de vista do empresário é uma questão que vem antes da sobrevivência do meio ambiente, todavia os aspectos econômicos, sociais e ambientais precisam ser analisados em conjunto.

Para Schenini, Cardoso e Rensi (2005, p. 36) "a empresa utiliza recursos disponibilizados pela natureza e sociedade, através de suas atividades produtivas, e retorna produtos e serviços para a mesma. Mas estes processos produtivos, além de riquezas, geram custos sociais e ambientais".

Torres (2001, p. 19) evidencia que "a discussão em torno da atuação social das empresas e da construção de uma ética empresarial acabou tendo consequências concretas: muitas empresas começaram a investir em áreas sociais, tradicionalmente ocupadas somente pelo Estado."

A Associação Brasileira de Normas Técnicas (ABNT) por meio da ISO 16.000 utiliza o conceito de que a Responsabilidade Social está diretamente associada à concepção de desenvolvimento sustentável, e que refletirá nas dimensões econômica, ambiental e social.

Conforme Monteiro e Ferreira (2007, p. 87):

com relação à evidenciação da informação ambiental, pode-se afirmar que seu objetivo é divulgar, para os stakeholders, informações sobre o desempenho das entidades nas questões ambientais, bem como divulgar toda a informação que afete o meio e o patrimônio das entidades.

As informações a serem divulgadas precisam transparecer as ações e práticas empresariais, enfatizando a responsabilidade social e ambiental da entidade, a postura e compromisso para com a sociedade e meio ambiente.

O estudo de Barbieri et al. (2010) analisa a relação entre sustentabilidade e inovação abordando a relação entre sustentabilidade e inovação, destacando a importância das empresas buscarem por inovação visando sua permanência no mercado, todavia precisam considerar as três dimensões da sustentabilidade - social, ambiental e econômica.

No Brasil a Norma Brasileira de Contabilidade NBC T15 - Informações de Natureza Social e Ambiental, criada pela Resolução CFC n ${ }^{\circ} 1.003 / 2004$, normatizou a Demonstração de Informações de Natureza Social e Ambiental, com o objetivo de demonstrar à sociedade a participação e a responsabilidade social das entidades por meio das informações de natureza social e ambiental.

\subsection{Gestão Social e Ambiental}

Neste contexto a contabilidade torna-se o instrumento de apoio à gestão das informações sociais e ambientais, pois registra, mensura e evidencia os gastos, investimentos, receitas e despesas sociais e ambientais, relacionados aos projetos, ações e práticas empresariais.

Segundo Tinoco e Kraemer (2004) a contabilidade ambiental por meio dos registros das atividades operacionais, destaca os gastos e ações ambientais, compromissos futuros relacionados ao meio ambiente, bem como, focaliza nas medidas preventivas para reforçar a imagem da entidade perante a opinião pública e evitar problemas legais para o futuro. 
Para Ribeiro e Souza (2003), a contabilidade evidenciará os ativos e passivos ambientais, de forma a evidenciar os direitos e os sacrifícios realizados pela entidade para a preservação, recuperação e proteção do meio ambiente.

A partir das informações contábeis conforme Ferreira (2003) a gestão ambiental atingirá seus objetivos, em superar, anular ou diminuir os custos das degradações, causados no decorrer das atividades das entidades.

De acordo com Mazzioni, Di Domenico e Zanin (2010), a contabilidade possibilita a evidenciação das práticas de ações de responsabilidade social, apresentadas nas informações do balanço social, sendo este um demonstrativo que evidencia informações de caráter econômico, financeiro, social e ambiental, atendendo aos diferentes interesses e grupos de usuários.

Muitas empresas já estão buscando instrumentos de apoio e suporte a gestão, visando mensurar e acompanhar as ações e práticas sociais e ambientais, neste sentido a elaboração e acompanhamento do balanço social possibilita aos stakeholders à análise da conduta empresarial e os efeitos das atividades no meio onde se insere.

O estudo de Mazzioni, Tinoco e Oliveira (2007) apresenta uma proposta de balanço social para as fundações universitárias, observando as características específicas destas entidades. Segundo Pfitscher (2004) a sustentabilidade ambiental relaciona-se aos valores dos indivíduos nas atividades de cada organização, num processo contínuo de gestão ambiental, e neste sentido a adoção de um sistema de gestão ambiental (SGA) normalmente estabelece um comprometimento maior entre todos os envolvidos: empregados, fornecedores e clientes.

Para Tinoco e Kraemer (2004), um SGA incluirá a estrutura da entidade, bem como as atividades de planejamento, os procedimentos e práticas visando minimizar ou eliminar os efeitos negativos provocados por suas atividades ao meio ambiente.

Como exemplo de SGA pode-se citar o Sistema Contábil-Gerencial Ambiental SICOGEA, conforme o estudo de Pfitscher (2004) que registra o desenvolvimento do SiCOGEA na cadeia produtiva do arroz ecológico.

As três etapas do SICOGEA estão evidenciadas a seguir no Quadro 01:

\begin{tabular}{|l|l|}
\multicolumn{1}{|c|}{ Quadro 01 - Etapas do SICOGEA } \\
\hline Etapas da Proposta & \multicolumn{1}{|c|}{ Descrição } \\
\hline Integração da Cadeia & $\begin{array}{l}\text { Envolvimento da cadeia produtiva. Alinhamento da cadeia de } \\
\text { suprimentos envolvendo a identificação das necessidades dos } \\
\text { clientes e fornecedores. }\end{array}$ \\
\hline Gestão de Controle Ecológico & $\begin{array}{l}\text { Implementação da gestão ecológica e dos processos para a } \\
\text { certificação. }\end{array}$ \\
\hline $\begin{array}{l}\text { Gestão da Contabilidade e } \\
\text { Controladoria Ambiental }\end{array}$ & $\begin{array}{l}\text { Avaliação dos efeitos ambientais capazes de relacionar aspectos } \\
\text { operacionais, econômicos e financeiros da gestão (investigação e } \\
\text { mensuração); avaliação dos setores da empresa (informação) e } \\
\text { implementação de novas alternativas para a continuidade do } \\
\text { processo (decisão). }\end{array}$ \\
\hline
\end{tabular}

Fonte: Pfitscher (2004) apud VARGAS. et al. (2010, p. 12)

O estudo de Vargas et al. (2010) apresenta uma relação de 35 estudos realizados na forma de trabalhos de conclusão de curso (TCC) e artigos sobre o SICOGEA, publicados no período de 2003 a 2009. Aponta 24 TCC e 11 artigos por atividade, sendo que $25,71 \%$ ou 9 destes, são estudos realizados em hospitais, e apenas 2 estudos que representam $5,71 \%$ do total, ocorreram com a aplicação do SICOGEA em instituição de ensino.

O estudo de Pieri (2010) aplica o método SICOGEA- Geração 3 em uma instituição de ensino superior analisando a sustentabilidade da entidade a partir de uma lista de verificação e da mensuração dos critérios do método. 
O estudo de Uhlmann (2011) apresenta a aplicação e alterações para o SICOGEA, Geração 3, bem como destaca a eficiência do SICOGEA na identificação dos pontos críticos da sustentabilidade, além de auxiliar na estruturação de um plano de gestão ambiental voltado às medidas de proteção, recuperação e/ou reciclagem.

\subsection{Instituições de Ensino superior}

As instituições de ensino superior, reconhecidas e organizadas como Universidades, Faculdades ou Centros de Ensino, são juridicamente constituídas no formato público ou privado, e uma nova discussão caminha para o reconhecimento de um terceiro modelo, o das comunitárias ou instituições públicas não estatais.

O conceito de universidade conforme Chaui (2003, p.1) é de uma "instituição social e como tal exprime de maneira determinada a estrutura e o modo de funcionamento da sociedade como um todo."

Neste contexto instituições de ensino superior reconhecidas por universidades diferem-se por sua atuação com o ensino, pesquisa e extensão em prol do desenvolvimento sustentável do meio onde se inserem.

Segundo Costa, Almeida, Freitas (2010, p. 2), "a universidade que pratica esse tripé é detentora da grande virtude do compromisso social, pois consegue assimilar as demandas sociais e incorporá-las em seus currículos e ações."

De acordo com Peter, Therrien e Petter (2003, p. 4) a "autonomia administrativa, ou seja, a liberdade de organizar-se internamente é condição para o exercício pleno das dimensões didática e científica." Esta condição permite flexibilidade as instituições públicas, quanto à sua organização de seus gastos e investimentos.

Pegoraro (2009) enfatiza as particularidades das instituições comunitárias, quanto ao atendimento das determinações legais e faz referência aos modelos de instituições públicas não-estatais de Santa Catarina e do Rio Grande do Sul. Onde estas iniciaram suas atividades como fundações criadas pela comunidade e poder público, visando o desenvolvimento regional.

Para Lima (2009, p. 103):

uma universidade socialmente responsável, que concaminha com suas congêneres na busca da excelência da gestão de seus talentos humanos e de seus recursos ambientais, da formação acadêmica de seu corpo discente, da produção do saber e dos modelos epistemológicos escolhidos e da participação no desenvolvimento sustentável da comunidade regional, necessita expandir seus intercâmbios e interrelacionamentos.

Independente de receberem recursos públicos ou terem a cobrança das mensalidades subsidiando seus serviços, como diferença entre as instituições públicas e privadas, ambas precisam cumprir seu papel em prol do desenvolvimento regional onde se inserem, promovendo à ética e a justiça, bem como, respeitando e atendendo as demandas sociais e ambientais.

Segundo Schmidt e Campis (2009) no Estado de Santa Catarina existem 14 fundações educacionais configuradas como instituições comunitárias, bem como em nível nacional são 52 instituições, criadas a partir de iniciativas da comunidade com o apoio do governo de cada Estado e das Prefeituras.

O modelo de educação das instituições comunitárias contribui para que o Estado de Santa Catarina apresente um dos melhores índices de desenvolvimento humano conforme dados do Sistema ACAFE (2011) e ocupe o segundo lugar em matrículas na educação superior no Brasil. 


\section{Aspectos Metodológicos}

O estudo foi realizado a partir da aplicação do SICOGEA - Geração 3 em uma instituição de ensino superior com mais de 7.000 alunos, localizada no Oeste do Estado de Santa Catarina, a Unochapecó.

Como instrumento de coleta de dados, utilizou-se a lista de verificação desenvolvida por Pieri (2010), a qual possui 154 questões para análise da sustentabilidade ambiental das instituições de ensino.

A partir dessa lista de verificação, realizou-se a aplicação de entrevistas com base em um questionário aos responsáveis de diversos setores da universidade, tais como a Comissão Própria de Avaliação -CPA, Setor de Manutenção e Obras, Diretoria de Desenvolvimento Humano (DDH), Viveiro Florestal, Central de Resíduos, Setor de Compras, Vice-Reitoria de Administração (Vice Adm), Setor de Contabilidade; além de análise documental realizada pelo pesquisador, visando identificar as práticas sociais e ambientais da instituição. O Quadro 02 aponta os respondentes em cada critério analisado.

Quadro 02 - Respondentes por critérios analisados

\begin{tabular}{|c|c|}
\hline Critérios analisados & Respondentes \\
\hline Critério 1 - Fornecedores/compras & $\begin{array}{l}\text { Setor de compras (4 compradores } \\
\text { responsáveis por áreas diferentes); }\end{array}$ \\
\hline Critério 2 - Ecoeficiência do processo de prestação de serviço & $\begin{array}{l}\text { Vice Adm, DDH, Central de Resíduos, } \\
\text { Viveiro Florestal, Setor de Manutenção e } \\
\text { Obras, Setor de Compras; }\end{array}$ \\
\hline Critério 3 - Prestação do serviço - atendimento ao acadêmico & Setor de compras, CPA e Vice Adm; \\
\hline Critério 4 - Responsabilidade social na instituição & Central de resíduos, CPA e Vice Adm; \\
\hline Critério 5 - Gestão estratégica da instituição & Pesquisador, CPA e Vice Adm; \\
\hline Critério 6 - Indicadores gerenciais & Pesquisador, Contabilidade e Vice Adm; \\
\hline Critério 7 - Recursos humanos na instituição & $\mathrm{DDH}$ \\
\hline Critério 8 - Indicadores contábeis & Contabilidade e Vice Adm; \\
\hline a) indicadores ambientais de bens e direitos e obrigações & Contabilidade e Vice Adm; \\
\hline b) indicadores ambientais de contas de resultados & Contabilidade e Vice Adm; \\
\hline c) indicadores de demonstração ambiental específica & Contabilidade e Vice Adm; \\
\hline Critério 9 - Auditoria ambiental & $\begin{array}{c}\text { Pesquisador, Contabilidade, Viveiro Florestal } \\
\text { e Vice Adm; }\end{array}$ \\
\hline Total de questões & 154 \\
\hline
\end{tabular}

Fonte: dados da pesquisa (2011)

A partir das 154 respostas da lista de verificação, coletadas durante o mês de julho e agosto de 2011, realizou-se a análise qualitativa das questões, visando relacioná-las aos pontos possíveis, sendo que utilizou-se as escalas de 0 a 5 ou $0 \%$ a $100 \%$, onde 0 para situações onde não demonstra nenhum investimento ou ação sobre o tema avaliado, sendo 1 ou $20 \%$ para fracas situações de investimentos ou controle, 2 ou $40 \%$ para pouco um pouco maior que as situações "fracas", 3 ou $60 \%$ para situações que demonstra médio ou mais que o item anterior em investimentos e controles; 4 ou $80 \%$ quando a empresa demonstra forte 
investimentos e controles e escala 5 ou $100 \%$ quando a empresa possui alto nível de investimentos e controles ambientais ou nas situações analisadas.

Para o cálculo da sustentabilidade ambiental utilizou-se a seguinte fórmula:

$$
\text { Índice geral de sustentabilidade }=\frac{\text { pontos alcançados }}{\text { pontos possíveis }}
$$

Figura 1 - Fórmula do cálculo da sustentabilidade

Fonte: adaptada de Nunes (2010, p. 172, apud Uhlmann 2011, p. 113)

Por meio da fórmula apresentada foi possível identificar o índice de sustentabilidade ambiental de cada um dos 9 critérios analisados pelo SICOGEA- Geração III, bem como o índice geral de sustentabilidade ambiental da instituição de ensino em análise.

A Tabela 1 aponta a interpretação a ser obtida a partir da análise dos resultados obtidos, conforme cada percentual obtido a partir do SICOGEA.

Tabela 1 - Avaliação da sustentabilidade e desempenho ambiental segundo o SICOGEA

\begin{tabular}{l|l|l}
\hline Resultado & Sustentabilidade & \multicolumn{1}{c}{ Desempenho: controle, incentivo, estratégia } \\
\hline Inferior a 20\% & Péssima - 'P' & Pode estar causando grande impacto ao meio ambiente \\
\hline Entre 21 e 40\% & Fraca - 'F' & $\begin{array}{l}\text { Pode estar causando danos, mas surgem algumas poucas } \\
\text { iniciativas }\end{array}$ \\
\hline Entre 41 e 60\% & Regular - 'R' & Atende somente à legislação \\
\hline Entre 61 e 80\% & Boa - 'B' & $\begin{array}{l}\text { Além da legislação, surgem alguns projetos e atitudes que buscam } \\
\text { valorizar o meio ambiente }\end{array}$ \\
\hline Superior a $80 \%$ & Ótima - 'O' & $\begin{array}{l}\text { Alta valorização ambiental com produção ecológica e prevenção } \\
\text { da poluição }\end{array}$ \\
\hline
\end{tabular}

Fonte: adaptada de Lerípio (2001), Pfitscher (2004) e Nunes (2010) apud Uhlmann (2011)

Após a realização e preenchimento das questões da lista de verificação adaptada de Pieri (2011), utilizou-se os critérios de avaliação do SICOGEA - Geração 3 para avaliar o índice de sustentabilidade e desempenho ambiental da instituição em análise, atendendo aos 9 critérios de análise propostos por Pieri (2011) para instituições de ensino.

\section{Análise dos Resultados}

Neste tópico aborda-se um breve histórico da instituição de ensino onde se realizou a análise de sua sustentabilidade, a partir da aplicação parcial do SICOGEA, Geração 3.

\subsection{Breve histórico da instituição estudada}

A Universidade Comunitária da Região de Chapecó - Unochapecó é uma instituição de ensino situada na região oeste do Estado de Santa Catarina, no Município de Chapecó, com extensões nos Municípios de São Lourenço do Oeste e Xaxim.

A Unochapecó (2011) configura-se como uma instituição de ensino comunitária com uma história de 40 anos no ensino superior. Na atualidade possui cerca de 8.000 alunos entre graduação e pós-graduação, um quadro funcional com 496 docentes e 374 técnicosadministrativos. Possui mais de 40 cursos de graduação, cerca de 39 cursos de pós-graduação lato-sensu e três programas de mestrados. Já formou mais de 15.000 profissionais nas mais diversas áreas.

A Instituição possui uma editora a Argos, a qual já publicou mais de 200 livros, bem como, a Unochapecó possui 15 programas de extensão, 52 projetos de extensão e beneficia 
mais de 2.000 alunos com bolsas de estudos, atendendo seu compromisso e sua missão voltada a produção e difusão do conhecimento em prol do desenvolvimento regional sustentável.

A Unochapecó elabora e publica o Balanço Social, desde o ano de 2002 como forma de evidenciar suas ações, projetos e práticas voltadas à comunidade regional e ao meioambiente.

\subsection{Aplicação do SICOGEA - Geração 3}

Após a coleta das informações junto aos responsáveis por setores ou departamentos da instituição, seguindo o roteiro da lista de verificação de Pieri (2011), foi possível identificar os índices de sustentabilidade da instituição objeto do estudo, atendendo a 9 critérios estabelecidos.

A Tabela 02 apresenta os índices de sustentabilidade obtidos por critério a partir do SICOGEA - Geração 3.

Tabela 02 - Resumo da lista de verificação - SICOGEA- Geração 3

\begin{tabular}{|c|c|c|c|c|}
\hline \multirow{2}{*}{ CRITÉRIOS } & \multirow{2}{*}{$\begin{array}{c}\text { Pontos } \\
\text { Possíveis }\end{array}$} & \multirow{2}{*}{$\begin{array}{c}\text { Pontos } \\
\text { Alcançados }\end{array}$} & \multicolumn{2}{|c|}{ Sustentabilidade } \\
\hline & & & Índice & Avaliação \\
\hline Critério 1 - Fornecedores/compras & 18 & 11,6 & $64,4 \%$ & Bom \\
\hline $\begin{array}{l}\text { Critério } 2 \text { - Ecoeficiência do processo de } \\
\text { prestação de serviço }\end{array}$ & 65 & 42 & $61,5 \%$ & Bom \\
\hline $\begin{array}{l}\text { Critério } 3 \text { - Prestação do serviço - } \\
\text { atendimentos ao acadêmico }\end{array}$ & 13 & 11,6 & $89,2 \%$ & Ótimo \\
\hline $\begin{array}{l}\text { Critério } 4 \text { - Responsabilidade social na } \\
\text { instituição }\end{array}$ & 18 & 14,8 & $82,2 \%$ & Ótimo \\
\hline $\begin{array}{l}\text { Critério } 5 \text { - Gestão estratégica da } \\
\text { instituição }\end{array}$ & 16 & 12,2 & $78,8 \%$ & Bom \\
\hline Critério 6 - Indicadores gerenciais & 15 & 10,4 & $74,7 \%$ & Bom \\
\hline $\begin{array}{l}\text { Critério } 7 \text { - Recursos humanos na } \\
\text { instituição }\end{array}$ & 23 & 18 & $78,3 \%$ & Bom \\
\hline Critério 8 - Indicadores contábeis & 35 & 23,2 & $66,3 \%$ & Bom \\
\hline $\begin{array}{l}\text { a) indicadores ambientais de bens e } \\
\text { direitos e obrigações }\end{array}$ & 11 & 7,8 & $70,9 \%$ & Bom \\
\hline $\begin{array}{l}\text { b) indicadores ambientais de contas de } \\
\text { resultados }\end{array}$ & 7 & 3,4 & $77,1 \%$ & Bom \\
\hline $\begin{array}{l}\text { c) indicadores de demonstração } \\
\text { ambiental específica }\end{array}$ & 17 & 12 & $70,6 \%$ & Bom \\
\hline Critério 9 - Auditoria ambiental & 39 & 27 & $65,1 \%$ & Bom \\
\hline Total Geral da Instituição & 242 & 170,8 & $\mathbf{7 0 , 4 \%}$ & Bom \\
\hline
\end{tabular}

Fonte: adaptada de Pieri (2011)

Com relação ao critério 1- Fornecedores, observou-se que a instituição pode buscar melhorar seus processos de compras buscando por fornecedores que estejam comprometidos 
com o ciclo de vida dos produtos, e possam auxiliar no descarte destes, principalmente os eletrônicos ou da construção civil.

No segundo critério observado com relação à ecoeficiência do processo de prestação de serviços percebe-se que a instituição pode incrementar diversas políticas instituições ou ações junto aos setores visando à conscientização do consumo dos materiais e da compra de produtos com maior eficiência energética e menor impacto ambiental.

Os grupos 3- Prestação de Serviço- atendimento ao acadêmico, e grupo 4 Responsabilidade social na instituição; foram àqueles que mais contribuíram para a avaliação geral da instituição, tendo em vista que respectivamente alcançaram 89,2\% e 82,2\%, considerados ótimos, ou seja, cumpre seu papel sustentável atingindo alta valorização ambiental com produção ecológica e prevenção da poluição.

Os critérios 5 a 9 também refletem a importância do acompanhamento da análise e acompanhamento das práticas ambientais, tendo em vista, que a comunidade interna e externa precisa ser informada de programas, projetos e ações desenvolvidas pela gestão visando minimizar os impactos ambientais causados pelas atividades, bem como, esta comunidade também precisa sentir-se responsável por suas ações cotidianas e agir de forma consciente; por isso investir em conscientização ambiental e buscar as melhores praticas é um dever ético da instituição.

Diante da análise realizada a partir do SICOGEA, com relação a cada critério estabelecido, podem-se constatar pontos favoráveis e desfavoráveis em cada um dos critérios analisados. Visando contribuir com à implementação de ações e práticas voltadas a melhoria dos índices de sustentabilidade ambiental na instituição objeto do estudo, apresenta-se a seguir um resumo dos pontos fortes observados ou ações já desenvolvidas pela instituição, as principais fragilidades e propostas de ações a serem desenvolvidas de acordo com cada critério observado pelo estudo.

Quadro 03 - Propostas de ações a serem desenvolvidas

\begin{tabular}{|c|c|c|c|}
\hline $\begin{array}{c}\text { Critérios } \\
\text { analisados na } \\
\text { instituição de } \\
\text { ensino }\end{array}$ & $\begin{array}{l}\text { Principais Pontos Fortes } \\
\text { observados }\end{array}$ & $\begin{array}{l}\text { Principais Fragilidades } \\
\text { observadas }\end{array}$ & $\begin{array}{l}\text { Propostas de ações a serem } \\
\text { desenvolvidas }\end{array}$ \\
\hline $\begin{array}{l}\text { Critério } 1 \text { - } \\
\text { Fornecedores } \\
\text { /compras }\end{array}$ & $\begin{array}{c}\text { O Setor de compras é } \\
\text { organizado por área, e } \\
\text { observa-se a eficiência } \\
\text { energética dos produtos } \\
\text { eletroeletrônicos. }\end{array}$ & $\begin{array}{l}\text { Ainda são tímidas as } \\
\text { iniciativas dos } \\
\text { fornecedores com o meio } \\
\text { ambiente a preocupação } \\
\text { com os resíduos. }\end{array}$ & $\begin{array}{c}\text { Incrementar a seleção de } \\
\text { fornecedores buscando observar } \\
\text { que estes atendam aos critérios de } \\
\text { responsabilidade social e } \\
\text { mantenham processos adequados de } \\
\text { produção e destino dos resíduos de } \\
\text { produção. }\end{array}$ \\
\hline $\begin{array}{l}\text { Critério 2- } \\
\text { Ecoeficiência do } \\
\text { processo de } \\
\text { prestação de } \\
\text { serviço }\end{array}$ & $\begin{array}{c}\text { Possui uma Central de } \\
\text { Resíduos que dá o destino } \\
\text { de acordo com a natureza } \\
\text { dos resíduos. Possui } \\
\text { Tratamento biológico dos } \\
\text { esgotos, capta e aproveita } \\
\text { a água da chuva, tem } \\
\text { coleta seletiva de lixo }\end{array}$ & $\begin{array}{l}\text { Destino para os resíduos } \\
\text { gerados pela construção } \\
\text { civil; conscientização da } \\
\text { comunidade interna e } \\
\text { externa. }\end{array}$ & $\begin{array}{l}\text { Continuar investindo na capacitação } \\
\text { de pessoas e na seleção de novas } \\
\text { técnicas que melhorem o destino } \\
\text { dos resíduos gerados pelas diversas } \\
\text { atividades. Programa de divulgação } \\
\text { das ações e práticas adotadas } \\
\text { visando conscientizar pelos } \\
\text { exemplos. }\end{array}$ \\
\hline $\begin{array}{l}\text { Critério } 3 \text { - } \\
\text { Prestação do } \\
\text { serviço - } \\
\text { atendimento ao } \\
\text { acadêmico }\end{array}$ & $\begin{array}{l}\text { Central de Atendimento } \\
\text { ao acadêmico, salas de } \\
\text { aulas e laboratórios } \\
\text { equipados e adequados } \\
\text { para portadores de } \\
\text { necessidades especiais. } \\
\text { Observância da } \\
\text { capacidade de pessoas por } \\
\text { ambiente. Gestão }\end{array}$ & $\begin{array}{l}\text { Alguns ambientes ainda } \\
\text { precisam de ajustes para } \\
\text { atender os portadores de } \\
\text { necessidades especiais. }\end{array}$ & $\begin{array}{l}\text { Observância de mudanças aos dos } \\
\text { espaços que ainda não atendam aos } \\
\text { portadores de necessidades } \\
\text { especiais, bem como, número de } \\
\text { vagas de estacionamento cobertas e } \\
\text { identificadas para estes. Divulgação } \\
\text { dos programas e projetos que } \\
\text { permitam a participação de } \\
\text { estudantes em atividade artísticas e }\end{array}$ \\
\hline
\end{tabular}




\begin{tabular}{|c|c|c|c|}
\hline & $\begin{array}{l}\text { democrática em todos às } \\
\text { instâncias da instituição. }\end{array}$ & & culturais. \\
\hline $\begin{array}{l}\text { Critério } 4 \text { - } \\
\text { Responsabilidade } \\
\text { social na } \\
\text { instituição }\end{array}$ & $\begin{array}{l}\text { Instituição comunitária, } \\
\text { divulga pelo Balanço } \\
\text { Social suas ações desde } \\
\text { 2002. Realiza orçamento } \\
\text { e preocupa-se com a } \\
\text { sustentabilidade } \\
\text { financeira. }\end{array}$ & $\begin{array}{l}\text { A comunidade acadêmica } \\
\text { e externa nem sempre } \\
\text { conhecem todas as ações } \\
\text { e práticas desenvolvidas } \\
\text { pela instituição, bem } \\
\text { como, os projetos que } \\
\text { abrange. }\end{array}$ & $\begin{array}{l}\text { Investimentos em comunicação das } \\
\text { ações e praticas ambientais, bem } \\
\text { como a socialização das } \\
\text { experiências para a comunidade } \\
\text { acadêmica, visando conscientizar } \\
\text { pelos exemplos. }\end{array}$ \\
\hline $\begin{array}{l}\text { Critério } 5 \text { - } \\
\text { Gestão } \\
\text { estratégica da } \\
\text { instituição }\end{array}$ & $\begin{array}{l}\text { A missão da instituição } \\
\text { demonstra preocupação } \\
\text { com o meio ambiente, } \\
\text { bem como, o } \\
\text { planejamento estratégico } \\
\text { considera o meio } \\
\text { ambiente. }\end{array}$ & $\begin{array}{l}\text { A instituição ainda está } \\
\text { implantando um plano } \\
\text { diretor, o qual encontra-se } \\
\text { em fase de análise. Nem } \\
\text { todas as construções } \\
\text { consideram a } \\
\text { acessibilidade dos } \\
\text { espaços. }\end{array}$ & $\begin{array}{c}\text { Aprovar o plano diretor, implantar } \\
\text { novas políticas de capacitação dos } \\
\text { colaboradores, para destino e uso } \\
\text { adequado dos recursos disponíveis. } \\
\text { Divulgar ações e práticas } \\
\text { ambientais desenvolvidas pela } \\
\text { instituição por meio dos projetos, } \\
\text { cursos ou programas. }\end{array}$ \\
\hline $\begin{array}{l}\text { Critério } 6- \\
\text { Indicadores } \\
\text { gerenciais }\end{array}$ & $\begin{array}{l}\text { A instituição já foi } \\
\text { reconhecida por suas } \\
\text { práticas ambientais. } \\
\text { Possui uma política } \\
\text { ambiental aprovada. }\end{array}$ & $\begin{array}{c}\text { A instituição não possui } \\
\text { um Sistema de Gestão } \\
\text { Ambiental, apenas setores } \\
\text { e responsáveis pelo } \\
\text { destino dos resíduos, } \\
\text { porém não controla } \\
\text { despesas com a proteção } \\
\text { ambiental. }\end{array}$ & $\begin{array}{c}\text { Controlar investimentos e despesas } \\
\text { ambientais realizadas. Observar } \\
\text { normas ambientais. } \\
\text { Adotar um Sistema de Gestão } \\
\text { Ambiental que auxilie no } \\
\text { gerenciamento das ações } \\
\text { ambientais. }\end{array}$ \\
\hline $\begin{array}{l}\text { Critério } 7 \text { - } \\
\text { Recursos } \\
\text { humanos na } \\
\text { instituição }\end{array}$ & $\begin{array}{c}\text { Existe um plano de cargos } \\
\text { e salários para docentes e } \\
\text { técnicos administrativos } \\
\text { da instituição. }\end{array}$ & $\begin{array}{l}\text { Apenas } 8,32 \% \text { do quadro } \\
\text { é composto por doutores. } \\
\text { O plano está difundido } \\
\text { junto ao quadro de } \\
\text { colaboradores, porém não } \\
\text { junto ao Ministério do } \\
\text { Trabalho. }\end{array}$ & $\begin{array}{c}\text { Implementar políticas de } \\
\text { permanência e captação de } \\
\text { doutores, bem como a qualificação } \\
\text { docente e atingir as exigências para } \\
\text { manter o título de Universidade. } \\
\text { Melhorar o processo de avaliação } \\
\text { de desempenho. }\end{array}$ \\
\hline $\begin{array}{l}\text { Critério } 8 \text { - } \\
\text { Indicadores } \\
\text { contábeis }\end{array}$ & $\begin{array}{c}\text { Possui publicação do } \\
\text { Balanço Social anual, } \\
\text { desde 2002, utiliza o } \\
\text { modelo de Mazzioni } \\
\text { desde 2005. Não possui } \\
\text { multas ou processos } \\
\text { resultantes de danos } \\
\text { ambientais. }\end{array}$ & $\begin{array}{l}\text { Não realiza reservas para } \\
\text { contingências ambientais. } \\
\text { Não evidencia } \\
\text { separadamente salários, } \\
\text { despesas, custos ou } \\
\text { receitas ambientais. }\end{array}$ & $\begin{array}{l}\text { Qualificar o plano de contas e as } \\
\text { notas explicativas visando } \\
\text { contemplar e evidenciar } \\
\text { investimentos e gastos de natureza } \\
\text { ambiental, bem como projetos e } \\
\text { ações dessa natureza. }\end{array}$ \\
\hline $\begin{array}{l}\text { Critério } 9 \text { - } \\
\text { Auditoria } \\
\text { ambiental }\end{array}$ & $\begin{array}{l}\text { A instituição possui uma } \\
\text { política de qualidade } \\
\text { ambiental aprovada. } \\
\text { Possui comissões } \\
\text { constituídas analisando os } \\
\text { fluxos e destino dos } \\
\text { resíduos gerados. Possui } \\
\text { coleta seletiva e } \\
\text { tratamento dos resíduos. }\end{array}$ & $\begin{array}{c}\text { Não há controle de } \\
\text { projetos e pesquisas da } \\
\text { qualidade ambiental da } \\
\text { instituição, não há } \\
\text { auditoria. Nem todos os } \\
\text { setores estão envolvidos } \\
\text { ou cientes das ações e } \\
\text { práticas ambientais } \\
\text { desenvolvidas pela } \\
\text { instituição. }\end{array}$ & $\begin{array}{l}\text { Realizar auditoria ambiental dos } \\
\text { processos e fluxos estabelecidos, } \\
\text { visando agregar melhorias e } \\
\text { acompanhar os procedimentos. } \\
\text { Estabelecer um canal de } \\
\text { comunicação com a comunidade } \\
\text { interna externa das ações de } \\
\text { responsabilidade social praticadas } \\
\text { pela instituição. }\end{array}$ \\
\hline
\end{tabular}

Fonte: dados da pesquisa (2011)

O Quadro 3 evidencia os critérios analisados pelo SICOGEA, bem como, permite identificar de forma resumida algumas das principais práticas ambientais da instituição de ensino analisada e as diversas sugestões propostas, visando a implementação de ações em prol do meio ambiente, visando a melhoria do índice de sustentabilidade ambiental conforme o SICOGEA.

Kruger, S. D.; Pfitscher, E. D.; Uhlmann, V. O.; Petri, S. M. 
Os resultados do estudo de Pieri (2010) evidenciam a necessidade da instituição buscar fornecedores que atendam às questões voltadas a responsabilidade social, bem como, definir políticas de seleção, conscientização e punição para estes. O pesquisador ainda salienta a necessidade de implantação da coleta seletiva de lixo, tratamento da água da chuva e destino adequado dos resíduos, de elaboração de um plano diretor que proporcione melhoria das condições do transporte público e das vias de acesso à universidade, com a reivindicação junto ao poder público; visando melhorar o índice de sustentabilidade ambiental obtido de $67,80 \%$.

Comparando-se o índice obtido pelo presente estudo, junto a Unochapecó de 70,40\% observa-se que as ações de coleta seletiva de lixo, central de resíduos que organizam os destinos e tratam do acompanhamento adequado dos processos de cada tipo de resíduo, estrutura definida de um plano diretor, são os principais aspectos que contribuíram no desempenho ambiental obtido. Todavia, outras questões como a auditoria ambiental, seleção e critérios de contratação de serviços e fornecedores, conscientização da comunidade interna e externa, também são itens a serem melhorados pela instituição em análise, conforme as ações propostas no Quadro 03.

Por meio do SICOGEA- Geração 3, evidenciou-se um índice de sustentabilidade ambiental, o que possibilita aos gestores a análise de inúmeros aspectos relacionados ao meio ambiente e que se insere em diversos setores, refletindo que a responsabilidade social e ambiental precisa ser discutida e entendida como parte do processo gestão e as decisões nas diversas instâncias ou setores, devem considerar os impactos ambientais, visando sua redução ou a melhoria contínua. Neste sentido, não apenas para se obter um melhor índice de sustentabilidade ambiental, mas principalmente para refletir o compromisso institucional com o dever ético e responsável que todas as entidades deveriam atender.

\section{Conclusões e Sugestões para Futuros Trabalhos}

Por meio da aplicação da primeira fase da terceira etapa do SICOGEA - Geração 3, foi possível identificar como se encontra uma instituição catarinense de ensino superior, quanto a sustentabilidade ambiental. Identificou-se que a instituição objeto do estudo apresenta um índice geral de sustentabilidade ambiental considerado "Bom", com percentual de $70,4 \%$ de sustentabilidade ambiental.

Por meio da análise dos 9 critérios através da metodologia do SICOGEA - Geração 3, conforme lista de verificação de Pieri (2011), identificou-se que a instituição possui 2 critérios considerados ótimos ou indicadores adequados de sustentabilidade, sendo os critérios de Prestação de Serviço e atendimento ao acadêmico, com índice de $89,2 \%$ e o critério de Responsabilidade social na instituição com índice de $82,2 \%$; os quais contribuíram para a avaliação geral da instituição.

Como pontos fortes observados salienta-se que a instituição realizada possui coleta seletiva de lixo, possui uma central de resíduos que acompanha os processos e encaminha os resíduos aos destinos adequadamente regularizados, elabora e publica o Balanço Social e possui uma política de qualidade ambiental aprovada internamente. As principais fragilidades observadas se referem a necessidade da melhoria do processo de comunicação interna e externa, visando demonstrar sua responsabilidade social e ambiental, bem como a observância na seleção de fornecedores socialmente responsáveis, ainda a necessidade de auditorias ambientais e ajustes no plano de contas para a evidenciação de gastos ou receitas ambientais.

A partir das constatações evidenciadas no Quadro 03, realizaram-se propostas de ações que poderão ser desenvolvidas pela instituição de ensino, visando a melhoria de suas ações e práticas ambientais e consequentemente a sua imagem junto a comunidade interna e externa. 
O estudo limitou-se a análise da lista de verificação de Pieri (2010) desenvolvida para uma instituição de ensino com 154 questões, o que para futuros estudos ou para novas análises poderão ser modificadas ou incrementadas tais questões de análise, bem como, sugere-se para novos estudos a comparação entre outras instituições de ensino ou o confronto dos índices de sustentabilidade ambiental a partir da metodologia do SICOGEA Geração I ou Geração II e ainda estudos sobre A3P.

\section{Referências}

ASSOCIAÇÃO BRASILEIRA DE NORMAS TÉCNICAS. NBR 16000: responsabilidade social: sistema de gestão. Disponível em: http://abnt.org.br Acesso em 11 jul 2011.

CAMPOS, Simone Alves Pacheco de; ESTIVALETE, Vania de Fátima Barros; MACHADO, Marcelo dos Santos. Perspectivas da sustentabilidade e a relação com os stakeholders: um estudo envolvendo uma rede horizontal do segmento do varejo. Engema 2008 - X Encontro Nacional de Gestão Empresarial e Meio Ambiente. 9 a 12 nov 2008, Porto Alegre.

CHAUI, Marilena. A universidade pública sob nova perspectiva. Conferência de abertura da 26 ${ }^{a}$ reunião anual da ANPED. Poço de Caldas, 05 de out. 2003. Disponível em: $<$ http://www.anped.org.br/reunioes/26/marilenachauianped2003.doc > Acesso em: 07 jul. 2011.

CONSELHO FEDERAL DE CONTABILIDADE. Resolução CFC n ${ }^{\circ} 1.003$ de 19 de agosto de 2004. Aprova a NBC T 15 - Informações de natureza social e ambiental. Disponível em: <http://www.cfc.org.br>. Acesso em: 07 jul. 2011.

COSTA, Marvile Palis.; ALMEIDA, Maria Olívia Duarte Batistuta e; FREITAS, Terezinha Silva. Ensino, pesquisa e extensão: Compromisso social das universidades. Disponível em: <http://www.uftm.edu.br/upload/ensino/tcc teresinha.pdf > Acesso em: 07 jul. 2011.

FERREIRA, Aracéli Cristina de Souza. Contabilidade ambiental: uma informação para o desenvolvimento sustentável. São Paulo: Atlas, 2003.

FERREIRA, Elaine; CUNHA, Jorge; ROSSETTO, Carlos Ricardo. Adaptação estratégica e gestão ambiental: Um estudo das mudanças organizacionais em uma indústria de fundição da região de Joinville - SC. Engema 2008 - X Encontro Nacional de Gestão Empresarial e Meio Ambiente. 9 a 12 nov 2008, Porto Alegre.

PFITSCHER, Elisete Dahmer. Gestão e sustentabilidade através da contabilidade e controladoria ambiental: estudo de caso na cadeia produtiva de arroz ecológico. Florianópolis, 2004, 252 p. Tese (Doutorado em Engenharia da Produção) - Programa de PósGraduação em Engenharia da Produção, Universidade Federal de Santa Catarina, 2004.

NUNES, João Paulo de Oliveira. Um aporte ao sistema contábil gerencial ambiental: elaboração e aplicação parcial do novo sistema em clínica hospitalar. Dissertação apresentada ao Programa de Pós-Graduação em Contabilidade, do Centro Sócio-Econômico, da Universidade Federal de Santa Catarina, UFSC, 2010. 
LERÍPIO, Alexandre de Ávila. GAIA: um método de gerenciamento de aspectos e impactos ambientais. Florianópolis, 2001. Tese (Doutorado em Engenharia de Produção) Programa de Pós-Graduação em Engenharia da Produção, Universidade Federal de Santa Catarina, 2001.

LEONARDO, V. R. Um estudo sobre os gastos ambientais presentes na contabilidade de indústrias químicas brasileiras. Contabilidade Vista \& Revista., v. 17, n. 2, p. 89-109, abr./ jun. 2006.

LIMA, Luiz Gonzaga. Instituições comunitárias: instituições públicas não estatais. Santa Cruz do Sul: EDUNISC, 2009.

MAZZIONI, Sady; TINOCO, João Eduardo Prudêncio; OLIVEIRA, Antonio Benedito Silva. Proposta de um modelo de balanço social para fundações universitárias. BASE: Revista de Administração e Contabilidade da Unisinos. São Leopoldo, v. 4. n. 3, p. 274-285, set./dez. 2007.

MAZZIONI, Sady; DI DOMENICO, Daniela; ZANIN, Antonio. A evidenciação da prática corporativa de ações de responsabilidade social com o uso do balanço social. XVII Congresso Brasileiro de Custos - Belo Horizonte, MG, Brasil, 3 a 5 de novembro de 2010. Anais.

MONTEIRO, Paulo Roberto Anderson; FERREIRA, A. C. de Sousa. A evidenciação da informação ambiental nos relatórios contábeis: um estudo comparativo com o modelo do ISAR/UNCTAD. RGSA- Revista de Gestão Ambiental e Social. Vol 1, no 1. p.82-101, Janabr 2007.

NUNES, João Paulo de Oliveira. Um aporte ao sistema contábil gerencial ambiental: elaboração e aplicação parcial do novo sistema em clínica hospitalar. 2010. Dissertação (Mestrado em Contabilidade), Programa de Pós-Graduação em Contabilidade, Universidade Federal de Santa Catarina -UFSC, Florianópolis, 2010.

PEGORARO, Ludimar. Universidade e sociedade: sistema catarinense de educação superior. Atos de pesquisa em educação - ppge/me furb. V. 4, n ${ }^{\circ} 3$, p. 357-406, set./dez. 2009.

PETER, Maria da Gloria Arrais; THERRIEN, Jacques; PETER, Fabio Arrais. Aspectos do projeto político pedagógico institucional nas universidades federais brasileiras. Revista Brasileira de Educação. Set /Out /Nov /Dez 2003 n. 24.

PFITSCHER, Elisete Dahmer. Gestão e sustentabilidade através da contabilidade e controladoria ambiental: estudo de caso na cadeia produtiva de arroz ecológico. tese de doutorado, 2004. Disponível em http://www.nemac.ufsc.br/visualizar/teseelisete.pdf. Acesso em: 10 jul.2011.

RIBEIRO, Maisa de Souza; SOUZA, Ana Lucia Bertoli de. Passivo ambiental: estudo de caso da Petróleo Brasileiro S.A. - Petrobrás. A repercussão ambiental dos acidentes ocorridos nas Demonstrações Contábeis. In: ENANPAD, 27. 2003, Atibaia. São Paulo. 
SCHENINI, Pedro Carlos; CARDOSO, André Coimbra Felix; RENSI, Francini. Responsabilidade Social Corporativa. In: SCHENINI, Pedro Carlos. (Org.). Gestão empresarial sócio ambiental. Florianópolis: Nova Letra, 2005. p. 35-60.

SCHMIDT, João Pedro; CAMPIS, Luiz Augusto Costa a. Instituições comunitárias: instituições públicas não estatais. Santa Cruz do Sul: EDUNISC, 2009.

SISTEMA ACAFE. Disponível em: <http://www.universidadecomunitaria.com.br > Acesso em: 12 ago. 2011.

TINOCO, João Eduardo Prudêncio; KRAEMER, Maria Elisabeth Pereira. Contabilidade e gestão ambiental. São Paulo: Atlas, 2004.

TORRES, Ciro. Responsabilidade social das empresas (RSE) e balanço social no Brasil. In: SILVA, César Augusto Tiburcio; FREIRE, Fátima de Souza. (Org.). Balanço social: teoria e prática. São Paulo: Atlas, 2001. p. 15-30.

TREVISAN, Marcelo; MADRUGA, Lúcia Rejane da Rosa Gama; BLOCK, Alexander Souza; VICENTINI, Maria Medianeira. Trabalhando as dimensões social, ambiental e econômica da sustentabilidade: estudo de caso em um rodeio internacional. Engema 2008 X Encontro Nacional de Gestão Empresarial e Meio Ambiente. 9 a 12 nov 2008, Porto Alegre.

UHLMANN, Vivian Osmari. Contribuições ao desenvolvimento do sistema contábil gerencial ambiental - geração 2: proposição da geração 3 do método. Dissertação apresentada ao programa de pós-graduação em contabilidade da Universidade Federal de Santa Catarina. Florianópolis, 2011.

UNIVERSIDADE COMUNITARIA DA REGIÃO DE CHAPECÓ. Fundação Universitária do desenvolvimento do Oeste. Disponível em: 〈http://www.unochapeco.edu.br > Acesso em: 10 jul. 2011.

VARGAS, A. B. et al. Mapeamento dos aspectos considerados relevantes em estudos que abordam a aplicação do SICOGEA. Congresso Internacional de Administração. 2010, Ponta Grossa. 